\section{Changes in Root and Shoot Growth and Biomass Partition Resulting from Different Irrigation Intervals for Ligustrum japonicum Thunb.}

\author{
Dilma Daniela Silva ${ }^{1}$ \\ Mid-Florida Research and Education Center, IFAS, University of Florida, \\ 2725 S. Binion Road, Apopka, FL 32703
}

\author{
Michael E. Kane \\ Environmental Horticulture Department, University of Florida, Rm. 109 \\ Building 68, P.O. Box 110675, Gainesville, FL 32611-0675 \\ Richard C. Beeson, Jr. \\ Mid-Florida Research and Education Center, IFAS, University of Florida, \\ 2725 S. Binion Road, Apopka, FL 32703
}

Additional index words. water stress, root-to-shoot ratio, water availability, biomass allocation, landscape stress

\begin{abstract}
Although effects of irrigation frequency and volumes on overall plant establishment and growth have been reported, previous research has not examined how intermittent exposure to substrate water limitation affects partitioning of growth between root tips and buds and how this influences episodic growth patterns. The research presented here examines these effects on Ligustrum japonicum during the establishment period. Plants were exposed to two irrigation treatments: short wetting and drying cycles (SC, 2 days) and long wetting and drying cycles (LC, 7 days). Intermittent water limitations (LC) resulted in new shoot dry mass reductions of $\approx \mathbf{2 8 \%}$ compared with well-irrigated counterparts, particularly diminishing leaf growth. Water limitation effects on root-to-shoot ratio were dependent on plant growth stage. LC increased root-to-shoot ratios only when plants were at shoot flush, resulting in poor correlations $(r=\mathbf{0 . 5 3})$ between this ratio and differential percent volumetric water content, which was directly influenced by irrigation frequency. Patterns of shoot and root growth varied considerably between these clonal plants, which may be an important consideration on analyses of populations of woody plants. Large periods of episodic growth were not observed for most of the experimental period, but only after plant establishment. Root growth was similar in both treatments and there was no clear arresting of root growth during the experimental period. SC plants started bud expansion earlier than LC and had more shoot flushes and cumulative shoot growing points. A 7-day irrigation cycle was sufficient to establish two-year-old $L$. japonicum plants; however, shoot growth was less pronounced than root growth compared with plants irrigated on a 2-day cycle.
\end{abstract}

Trees and shrubs transplanted into the ground often undergo severe physiological shock because their capacity for water absorption is greatly decreased. Reduced capacity can be the result of a combination of factors such as injury to roots, loss of small absorbing roots, and disruption of the previously established contact of the root system with a large volume of soil (Beeson, 1994; Gilman and Beeson, 1996; Kozlowski and Pallardy, 2002). Furthermore, textural differences between the substrate used for container-grown plants and surrounding soil after transplant diminish the availability of water for root absorption (Spomer, 1974). As

Received for publication 21 May 2012. Accepted for publication 28 Aug. 2012.

${ }^{1}$ To whom reprint requests should be addressed; e-maildilma@ufl.edu.

(Kozlowski and Pallardy, 2002). In response to drought or limited soil moisture availability over extended periods, Thornley (1996) proposed that plant water status was more strongly influenced by changes in root-toshoot partitioning and root density than by the interaction of soil moisture content with stomatal conductance $\left(g_{\mathrm{S}}\right)$. McMillin and Wagner (1995) observed that the influence of water stress on root-to-shoot ratio is dependent on stage of development. Severe water stress applied during shoot flush resulted in increases in the root-to-shoot ratio of ponderosa pine seedlings. However, it did not affect root-to-shoot ratios when applied during root flush. Root-to-shoot ratio is also modified by natural growth patterns. Many woody species, such as Ligustrum japonicum Thunb., exhibit an episodic growth habit, fluctuating between periods of rapid shoot growth and slow root growth and periods with the inverse pattern (Kuehny and Halbrooks, 1993; Kuehny et al., 1997). Relatively little is known about changing carbon allocation patterns in species with episodic growth cycles (Dickson et al., 2000).

Plant response to water shortage varies with intensity as well as with the duration of stress (Farooq et al., 2009). The equilibrium between dehydration and photosynthetic activity is enabled by adaptation, acclimation, and short-term physiological regulation (Beikircher and Mayr, 2009). The major mechanism for dehydration avoidance depends on stress magnitude and duration. Plant adjustments to water availability include changes in morphological and anatomical features such as change in leaf angle, deposition of cuticle, shedding of leaves, and shifts in the allocation of resources between roots and shoots (Abrams, 1990; Kozlowski and Pallardy, 2002; Maseda and Fernandez, 2006; Mishio, 1992).

Increased drought tolerance occurs with the onset of osmotic adjustments after wetting and drying cycles (Kozlowski and Pallardy, 2002). Constant or slowly imposed water stress often inhibits photosynthesis for long periods resulting from stomatal closure (Saccardy et al., 1996) and consequently reduces plant height, biomass, and leaf area (Maseda and Fernandez, 2006). With time, development of a larger root system can exploit a greater volume of soil, thus increasing potential for water absorption. Moreover, increases in rootto-shoot ratio proportionally decrease the evaporation area of shoots relative to the absorptive area of roots.

The objective of this research was to determine how intermittent exposure to substrate water limitation affected dry matter partitioning and growth of L. japonicum during a simulated landscape establishment period. L. japonicum is a perennial species widely used as landscape hedges and as ornamental shrubs. More importantly, it exhibits moderate drought tolerance and provides an excellent model system for other species that partition assimilates through episodic shifts in root/shoot growth.

\section{Material and Methods}

The experiment was conducted in Apopka, natural light within an open-sided greenhouse $(6.1 \times 12.3 \mathrm{~m})$ with a clear inflated FL (lat. $28.688^{\circ} \mathrm{N}$, long. $86.53^{\circ} \mathrm{W}$ ) under 
double-polyethylene roof. There were no wind breaks except to the north, and the single layer polyethylene sides were generally rolled up to $2.5 \mathrm{~m}$ above the ground level, which was within $0.3 \mathrm{~m}$ of the roof line. Wind speeds were reduced by an unknown amount by the $30 \%$ black shadecloth attached along the east, south, and west sides. Polyethylene sides were rolled down to within $1 \mathrm{~m}$ of the ground immediately before thunderstorms and raised afterward. Daily reference evapotranspiration was calculated using Campbell Scientific's Application Note 4. Temperature and relative humidity were recorded using a CS-215 sensor (Campbell Scientific Inc., Logan, UT). Solar radiation was measured with a pyranometer (LI-200X; LI-COR Inc., Lincoln, NE). Daily climatic data were collected within $40 \mathrm{~m}$ of the experimental site.

Two-year-old clonal L. japonicum grown in 3.8-L containers were selected from a local nursery (Jon's Nursery, Eustis, FL) based on visual uniformity. In Feb. 2009, one plant was transplanted into each of 24 elevated star-shaped rhizotron (Silva and Beeson, 2011). A rhizotron had four arms and held $0.16 \mathrm{~m}^{3}$ of a commercial substrate composed of Canadian sphagnum peatmoss, processed pine bark, perlite, vermiculite, starter nutrients, wetting agents, and dolomitic limestone (Mix \#4; Conrad Fafard Inc., Agawan, MA). Rhizotrons measured $1.76 \mathrm{~m}$ across, $0.30 \mathrm{~m}$ deep at the end of each arm, and $0.35 \mathrm{~m}$ deep in the center. Each rhizotron had $40 \mathrm{~cm}$ of a wicking material (capillary system Aquamat ${ }^{\circledR}$; Soleno Textiles Inc., Laval, Quebec, Canada) extending below each arm in the center to remove excess moisture from the substrate. Irrigation to each rhizotron was controlled independently using a 24 VAC solenoid (Model 2400T; Irritrol, Riverside, CA) controlled by a data logger (CR10X; Campbell Scientific, Inc.) connected to a multiplexer (AM16/32B; Campbell Scientific, Inc.) and two remote relay controls (SDM-CD16AC; Campbell Scientific, Inc.). Irrigation was applied by a spray stake (Model green 22500-001120; Netafim Irrigation, Inc., Fresno, CA) at the tip of each arm pointing inward. The electric conductivity of irrigation water was $0.3 \mathrm{dS} \cdot \mathrm{m}^{-1}$. Plants were fertilized by hand monthly beginning $60 \mathrm{~d}$ after transplanting (DAT) with $500 \mathrm{~mL}$ of solution (3N:1P:2K, $198 \mathrm{mg} \cdot \mathrm{L}^{-1} \mathrm{~N}$ from $\mathrm{NH}_{4} \mathrm{NO}_{3}$, $66 \mathrm{mg} \cdot \mathrm{L}^{-1} \mathrm{P}$ from $\mathrm{K}_{2} \mathrm{HPO}_{4}$, and $133 \mathrm{mg} \cdot \mathrm{L}^{-1} \mathrm{~K}$ from $\mathrm{K}_{2} \mathrm{SO}_{4}$ ) delivered to the substrate surface after each irrigation.

Substrate moisture was measured within each rhizotron using one soil moisture sensor (EC-5 ECH $\mathrm{E}_{2} \mathrm{O}$ probe; Decagon Devices Inc., Pullman, WA) per rhizotron connected to the data logger system. Sensor calibration was based on the mean of five $\mathrm{ECH}_{2} \mathrm{O}$ probes. Measurements from each probe were collected over a range of 10 substrate moisture levels determined gravimetrically based on oven-dried $\left(70{ }^{\circ} \mathrm{C}\right)$ substrate mass. A single calibration curve was developed from collected measurements (Nemali et al., 2007). At plant transplanting into a rhizotron, the sensor was installed vertically adjacent to and half the depth of each root ball. Care was taken during sensor placement to ensure uniformity in depth and light surface compaction before settling the substrate around the sensor by adding $1.0 \mathrm{~L}$ of water applied to the surface above the sensor. Soil moisture sensors were relocated at 41 and 84 DAT to the edge of the expanding root system to compensate for root growth. The probe was pushed into undisturbed substrate down halfway and centered vertically and horizontally. Roots were undisturbed and were observed by opening the doors on the rhizotron's arms.

Plants were irrigated daily to allow for acclimatization and new root growth into the rhizotron substrate. Irrigation treatments began with irrigation of all rhizotrons at 41 DAT. This was when root tips were newly visible at the substrate profile of rhizotron arms. Thereafter treatments consisted of irrigation frequencies of once a week for $10 \mathrm{~min}$ (12 L of water, LC) or every other day for 5 min (6 L of water, SC) with 12 replications each (Fig. 1). Irrigation was initiated at $1930 \mathrm{~h}$ Eastern Standard Time near sunset.

To characterize variations of substrate moisture imposed by treatments, percent volumetric water content (\%VWC) was measured every $5 \mathrm{~min}$ by $\mathrm{ECH}_{2} \mathrm{O}$ probes and averages were recorded every $30 \mathrm{~min}$ using the data logger system. Volumetric water content at saturation $\left(\% \mathrm{VWC}_{\mathrm{Sat}}\right)$ was determined after each irrigation by averaging measurements recorded from 5 until $7 \mathrm{~h}$ after an irrigation. Minimum \%VWC (\%VWC $\left.\mathrm{Min}_{\mathrm{Min}}\right)$ was the average of the $2 \mathrm{~h}$ before an irrigation event. Differentials between $\% \mathrm{VWC}_{\text {Sat }}$ and $\% \mathrm{VWC}_{\text {Min }}\left(\Delta_{\% \mathrm{VWC}}\right)$ were calculated for each irrigation and averaged within replications.

Stomatal conductance was measured with a steady-state porometer (LI-1600) at 99, 101, and 105 DAT. Measurements were taken between sunrise and sunset in intervals of $2.25 \mathrm{~h}$ on three sun-exposed, fully expanded leaves from the first growth flush of the current growing season chosen at random on each plant replication (five plants per treatment). Stomatal conductance was measured for SC plants at 1 and $2 \mathrm{~d}$ after irrigation (days of minimum and maximum water stress, respectively) and for LC plants at 1,3 , and $7 \mathrm{~d}$ after irrigation (days of minimum, intermediary, and maximum water stress, respectively). Daily $g_{\mathrm{S}}\left(\mathrm{D} g_{\mathrm{S}}\right)$ was calculated in a similar manner as described for daily accumulative water stress (Beeson, 1992). Daily $g_{\mathrm{S}}$ for each plant was integrated each day by calculating the area under a $g_{\mathrm{S}}$ curve of each replicate. This parameter allowed for a simple comparison between treatments, which represented the potential quantity of water transpired during a day on a leaf area basis.

Shoot water potentials were determined in six plants of each treatment 143 and 144 DAT at predawn and midday with a pressure chamber (Model 3000; Soil Moisture Equipment Corp., Santa Barbara, CA) using compressed nitrogen gas. Measurement days corresponded to $1 \mathrm{~d}$ before and $1 \mathrm{~d}$ after irrigation. Measurements were made on individual twigs ( $\approx 10 \mathrm{~cm}$ long).

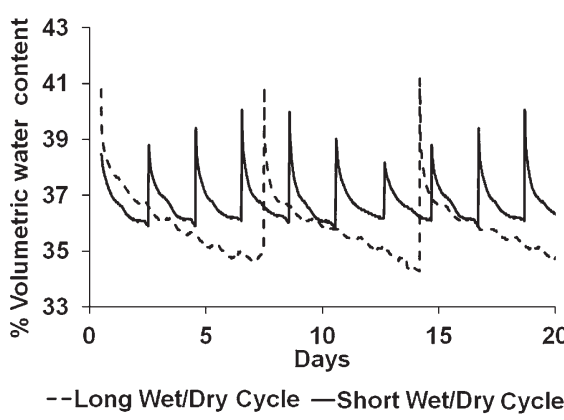

Fig. 1. Examples of percent volumetric water content recorded during a portion of the experimental period.

Growth of roots and shoots were monitored weekly and recorded after commencement. Growth was not disturbed by pruning during the experiment. The number of root growing points (RGP) visible in the eight rhizotrons' observation windows and the number of shoot growing points (SGP) were counted weekly throughout the experiments. A root growing point was defined as a root tip with visual characteristics of active growth (light color of the root cap, division and elongation zones, and no apparent root hairs). A shoot growing point was defined as a shoot tip between a visual budbreak and no unfolding of new leaves. Weekly plots of the number of growing root and shoot tips per irrigation treatment indicated when root flush and shoot flush harvest began. A flush was defined as the period between increasing and decreasing growing points until rest (zero value) or before a subsequent increase characterizing the beginning of a new flush. After harvest, plant material was oven-dried at $65{ }^{\circ} \mathrm{C}$ until a constant dry weight was obtained.

Dry masses and plant morphology parameters of six additional plants were determined at the beginning of the experiment. Number of leaves of all plants was recorded and average individual leaf area from these six additional plants was used to estimate total leaf area and leaf size of all plants. Leaf area; number of leaves; and dry mass of roots, leaves, and stems of old and new growth of plants grown in rhizotrons were measured at harvest. Leaf areas were measured using a LICOR 3100 leaf area meter (LI-COR, Lincoln, $\mathrm{NE}$ ). New leaves have very distinctive characteristics. New leaves are lighter green, less curled, and thinner than old leaves. Roots were divided between those that developed after transplant (referred as new roots) and roots from the root ball present at transplant (referred as old roots). Plants were harvested at 138 and 159 DAT. Six plants from each treatment were randomly chosen for harvest at root flush (increasing root growing points) and the rest at shoot flush (increasing shoot growing points).

Statistical analyses were conducted using the PROC GLM procedure. Growth measurements were analyzed as a randomized complete block with harvest dates 
as blocks and irrigation regime as treatments with six plant replicates. Mean separation was conducted using the Fisher's least significant difference $(P \leq 0.05)$. Maximum and minimum \%VWC were analyzed as repeated measurements over time. Pearson's correlation coefficient was calculated using CORR procedure in SAS. All statistical analyses were conducted using SAS (Version 9.1; SAS Institute, Cary, NC).

\section{Results and Discussion}

The polyethylene roof reduced solar radiation $17 \%$ at midday in May. Air temperature was measured sporadically and tended to be 1 to $2{ }^{\circ} \mathrm{C}$ higher than ambient during the day. Relative humidity was not measured inside the greenhouse. However, with only 24 plants occupying the $72-\mathrm{m}^{2}$ space, it was assumed to be near ambient.

Effect of water limitation on dry mass allocation. Plants exposed to LC predominantly limited production of aboveground components independent of the plant growth phase, yet both new and total root dry masses were similar between LC and SC plants at either harvest (Table 1). When subjected to LC vs. SC, new leaf dry mass was $\approx 31 \%$ less (Table 1), resulting in similar reductions in total leaf area (Table 2). At shoot flush, SC plants had $44 \%$ more new leaves than LC plants (Table 2). LC not only limited the number of new leaves, but also new and total leaf dry mass and leaf size measured at root flush. At transplant, existing leaves averaged $8.7 \mathrm{~cm}^{2}$. New leaves at root flush harvest were smaller for LC $\left(10.8 \mathrm{~cm}^{2}\right)$ than for SC plants $\left(13.7 \mathrm{~cm}^{2}\right)$, although individual new leaves had similar dry mass (Table 2). However, by shoot flush harvest $21 \mathrm{~d}$ later, all new leaves since root flush were of similar size for both treatments $\left(\approx 14 \mathrm{~cm}^{2}\right.$ and $\left.0.24 \mathrm{~g}\right)$. Similar leaf size indicates LC plants had established a sustainable balance between leaf area and root water absorption equivalent to SC plants after the root flush that occurred 17 weeks after transplanting. Scheiber et al. (2007) reported similar woody shrub species were established by 16 weeks when irrigated once every $7 \mathrm{~d}$ under similar rain-sheltered conditions. Leaves from shoot flushes before the root flush harvest experienced periods of higher water shortage than leaves developing between root and shoot flushes at the end of the experimental period. Limited leaf growth was the main contributor to reductions of $\approx 28 \%$ in dry mass of new shoots of LC plants compared with SC plants (Table 1) at the end of this experiment. Scheiber et al. (2007) reported that shoot dry mass was reduced $34 \%$ for Pittosporum tobira 'Variegata' and $73 \%$ for Viburnum odoratissimum by 7- vs. 2-d irrigation cycles. Shoot dry mass was reduced $70 \%$ when Cercidium floridum Benth. Ex A. Gray was irrigated on a 10- vs. 2-d irrigation schedule, whereas that of Caesalpinia pulcherrima L. was reduced 36\% (Stabler and Martin, 2006). Here total shoot mass between LC and SC plants was similar at root

Table 1. Dry mass (g) of components of Ligustrum japonicum grown in rhizotrons at two variable volumetric water contents developed through different frequencies of irrigation. ${ }^{\mathrm{z}}$

\begin{tabular}{|c|c|c|c|c|}
\hline & \multicolumn{2}{|c|}{ Root flush ${ }^{y}$} & \multicolumn{2}{|c|}{ Shoot flush ${ }^{\mathrm{x}}$} \\
\hline & Long wet/dry cyclew & Short wet/dry cycle & Long wet/dry cycle & Short wet/dry cycle \\
\hline \multicolumn{5}{|l|}{ Leaves } \\
\hline New & $53.6 \mathrm{c}^{\mathrm{u}}$ & $75.4 \mathrm{~b}$ & $67.8 \mathrm{bc}$ & $100.2 \mathrm{a}$ \\
\hline Total & $107 \mathrm{~b}$ & $132.8 \mathrm{ab}$ & $125.9 \mathrm{~b}$ & $158.2 \mathrm{a}$ \\
\hline \multicolumn{5}{|l|}{ Shoots ${ }^{t}$} \\
\hline New & $73.4 \mathrm{c}$ & $101 \mathrm{~b}$ & $93.2 \mathrm{bc}$ & $131.9 \mathrm{a}$ \\
\hline Total & $173.1 \mathrm{~b}$ & $207 \mathrm{~b}$ & $206.6 \mathrm{~b}$ & $259.7 \mathrm{a}$ \\
\hline \multicolumn{5}{|l|}{ Roots } \\
\hline New & $44.1 \mathrm{~b}$ & $47.4 \mathrm{~b}$ & $79.8 \mathrm{a}$ & $87.4 \mathrm{a}$ \\
\hline Total & $126.9 \mathrm{~b}$ & $131.7 \mathrm{~b}$ & $175.9 \mathrm{a}$ & $186.1 \mathrm{a}$ \\
\hline \multicolumn{5}{|c|}{ Total plant } \\
\hline New & $117.5 \mathrm{c}$ & $148.4 \mathrm{bc}$ & $173 \mathrm{~b}$ & $219.3 \mathrm{a}$ \\
\hline Total & $300 \mathrm{c}$ & $338.7 \mathrm{bc}$ & $382.5 \mathrm{ab}$ & $445.7 \mathrm{a}$ \\
\hline
\end{tabular}

${ }^{\text {zDry mass was quantified by plant harvest and component separation at the beginning of an increase in root }}$ growth activity (Root flush) or $21 \mathrm{~d}$ later at the beginning of bud burst (Shoot flush).

${ }^{y}$ One hundred thirty-eight days after transplant.

${ }^{\mathrm{x}}$ One hundred fifty-nine days after transplant.

${ }^{\text {w }}$ Seven-day irrigation cycles.

${ }^{v}$ Two-day irrigation cycles.

"Means of six replications. Means within rows not followed by the same letter are different at $P \leq 0.05$

(Fisher's least significant difference).

tShoots consisted of leaves and branches.

Table 2. Number of leaves, total leaf area, leaf size and leaf dry mass of new leaves of Ligustrum japonicum grown in rhizotrons at two variable volumetric water contents developed through different frequencies of irrigation. ${ }^{\mathrm{z}}$

\begin{tabular}{lccccc}
\hline & \multicolumn{2}{c}{ Root flush $^{\mathrm{y}}$} & & \multicolumn{2}{c}{ Shoot flush $^{\mathrm{x}}$} \\
\cline { 2 - 3 } \cline { 5 - 6 } & $\begin{array}{c}\text { Long wet/dry } \\
\text { cycle }^{\mathrm{w}}\end{array}$ & $\begin{array}{c}\text { Short wet/dry } \\
\text { cycle }\end{array}$ & & $\begin{array}{c}\text { Long wet/dry } \\
\text { cycle }\end{array}$ & $\begin{array}{c}\text { Short wet/dry } \\
\text { cycle }\end{array}$ \\
\hline Number of leaves & $288.8 \mathrm{~b}^{\mathrm{u}}$ & $372.3 \mathrm{ab}$ & & $284.6 \mathrm{~b}$ & $410.7 \mathrm{a}$ \\
Total leaf area $\left(\mathrm{cm}^{2}\right)$ & $3386 \mathrm{c}$ & $4967 \mathrm{ab}$ & & $3949 \mathrm{bc}$ & $5669 \mathrm{a}$ \\
Leaf size $^{\mathrm{t}}\left(\mathrm{cm}^{2}\right)$ & $10.8 \mathrm{~b}$ & $13.71 \mathrm{a}$ & & $14.19 \mathrm{a}$ & $13.73 \mathrm{a}$ \\
Leaf dry mass $(\mathrm{g})$ & $0.19 \mathrm{a}$ & $0.21 \mathrm{a}$ & & $0.25 \mathrm{a}$ & $0.24 \mathrm{a}$ \\
\hline
\end{tabular}

${ }^{\mathrm{x}}$ Dry mass was quantified by plant harvest and component separation at the beginning of an increase in root growth activity (Root flush) or $21 \mathrm{~d}$ later at the beginning of bud burst (Shoot flush).

y One hundred thirty-eight days after transplant.

${ }^{\mathrm{x}}$ One hundred fifty-nine days after transplant.

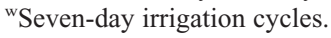

"Two-day irrigation cycles.

"Means of six replications. Means within rows not followed by the same letter are different at $P \leq 0.05$

(Fisher's least significant difference).

'Total leaf area divided by number of leaves.

Table 3. Allometric relationships and percentage of allocation in Ligustrum japonicum grown in rhizotrons at two variable volumetric water contents developed through different frequencies of irrigation. ${ }^{z}$

\begin{tabular}{|c|c|c|c|c|}
\hline & \multicolumn{2}{|c|}{ Root flush ${ }^{y}$} & \multicolumn{2}{|c|}{ Shoot flush ${ }^{x}$} \\
\hline & $\begin{array}{c}\text { Long wet/dry } \\
\text { cycle }^{w}\end{array}$ & $\begin{array}{c}\text { Short wet/dry } \\
\text { cycle }^{v}\end{array}$ & $\begin{array}{l}\text { Long wet/dry } \\
\text { cycle }\end{array}$ & $\begin{array}{c}\text { Short wet/dry } \\
\text { cycle }\end{array}$ \\
\hline Percent allocation to shoots & $57.4 \mathrm{ab}^{\mathrm{u}}$ & $61.3 \mathrm{a}$ & $54.1 \mathrm{~b}$ & $58.3 \mathrm{ab}$ \\
\hline Percent allocation to roots & $42.6 \mathrm{ab}$ & $38.7 \mathrm{~b}$ & $45.9 \mathrm{a}$ & $41.7 \mathrm{ab}$ \\
\hline Root-to-shoot ratio $\left(\mathrm{g} \cdot \mathrm{g}^{-1}\right)$ & $0.75 \mathrm{ab}$ & $0.64 \mathrm{~b}$ & $0.85 \mathrm{a}$ & $0.72 \mathrm{~b}$ \\
\hline Leaf area-to-root dry mass & $47.3 \mathrm{~b}$ & $57.8 \mathrm{a}$ & $38.8 \mathrm{~b}$ & $46.1 \mathrm{~b}$ \\
\hline
\end{tabular}

ratio $\left(\mathrm{cm}^{2} \cdot \mathrm{g}^{-1}\right)$

${ }^{2}$ Dry mass was quantified by plant harvest and component separation at the beginning of an increase in root growth activity (Root flush) or $21 \mathrm{~d}$ later at the beginning of bud burst (Shoot flush).

y One hundred thirty-eight days after transplant.

${ }^{\mathrm{x}}$ One hundred fifty-nine days after transplant.

weven-day irrigation cycles.

vTwo-day irrigation cycles.

"Means of six replications. Means within rows not followed by the same letter are different at $P \leq 0.05$ (Fisher's least significant difference).

flush but higher for SC plants at shoot flush (Table 1).

Allocation of photosynthates to shoots or roots was similar between irrigation regimes and plant stage of growth at each harvest (Table 3). Shoot allocation, however, was much lower than observed in ligustrum plants previously grown in the same rhizotrons but maintained near $100 \%$ plant available water. At that time dry mass distribution between above- and belowground portions of the plant was clearly toward shoot growth (Silva, 
2010). Earlier research reported similar shifts in allocation of new growth toward shoot growth for many woody plant species when under irrigation regimes that resulted in consistently high relative water contents of the plant (Beeson and Haydu, 1995). Later Kozlowski and Pallardy (2002) reviewed evidence of the reciprocal effect that drought promotes allocation of photosynthates to root growth. Both of these scenarios have been observed in L. japonicum, the preferential allocation to shoot growth described previously, and higher allocations to roots under fatal moisture limits (Silva, 2010).

Plants in the experiments reported here were harvested at the beginning of root or shoot flushes; thus, shoot flush harvest occurred after entire root flush(es) were complete, which increased root dry mass and resulted in reduced leaf area-to-root mass ratios. The higher root absorption area apparently enabled greater expansion of new LC leaves. This change in dry masses resulted in similar leaf area-to-root mass ratios for both treatments (Table 3). Similar ratios indicate that LC plants had established a balance between transpiring area and absorbing mass.

Root contributions to total biomass were generally $\approx 42 \%$ and varied marginally between moisture levels (Table 1). Many have

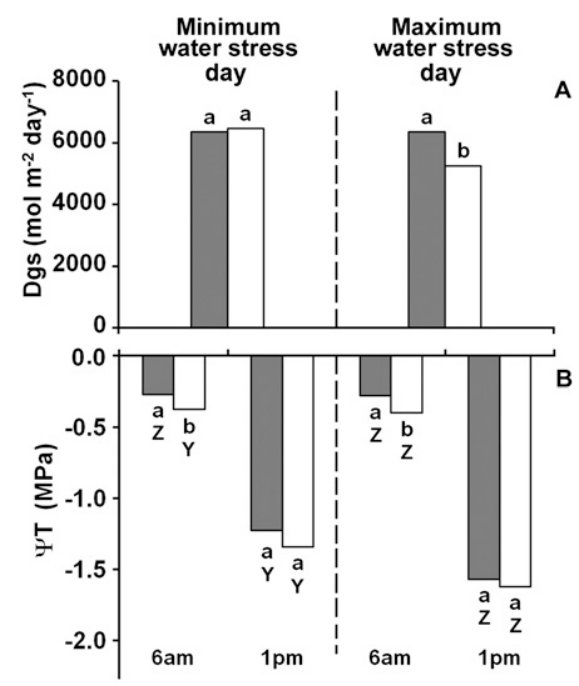

Short wet/dry cycle $\square$ Long wet/dry cycle

Fig. 2. (A) daily stomatal conductance $\left(\mathrm{D} g_{\mathrm{S}}\right)$ and (B) shoot water potential $\left(\Psi_{\mathrm{T}}\right)$ of Ligustrum japonicum grown under irrigation varying between saturation and 36.0 and $34.6 \%$ volumetric water content (VWC) for short wet/dry cycles (2-d irrigation cycles) and long wet/dry cycles (7-d irrigation cycles), respectively, on the day of minimum and maximum water stress. Each bar represents the mean of 15 daily curves of $\mathrm{D} g_{\mathrm{S}}$ (five plants $\times$ three leaves) and six replications of $\Psi_{\mathrm{T}}$. Bars not followed by the same lower case letter within each time are different at $P \leq 0.05$ (Fisher's least significant difference). Bars not followed by the same upper case letter within each treatment and between days at same measurement time are different at $P \leq 0.05$ (Fisher's least significant difference). suggested that water deficits ultimately result in plants with greater root-to-shoot ratios, thus greater capacity for water and mineral absorption relative to shoots (Chaves et al., 2003; Jackson et al., 2000; Kozlowski and Pallardy, 2002; Thornley, 1996). Results here indicate that irrigation on a 7-d cycle during the four months after an initial grow-in period did not change root-to-shoot ratios compared with irrigation on a 2-d cycle if plants were harvested during a root flush. However, the balance between root and shoot masses was influenced by water availability when plants were harvested at shoot flush (Table 3). LC plants harvested at shoot flush had significantly higher root-to-shoot ratio than SC plants harvested at the same stage of growth.
Root growth is less sensitive to water stress than is shoot growth (Sharp et al., 2004). Many plant species have been reported to respond to water stress with an increase in root-toshoot ratio, usually attributed to a decrease in shoot growth (Bachelard, 1986; Sharp and Davies, 1979; Steinberg et al., 1990). However, some authors attribute the change in rootto-shoot ratio under water shortage mainly to an adaptive improvement (drought tolerance) that is genetically inherited. These authors argue that leaf growth slows down, causing a decrease in foliage area and intercepted solar radiation (Farrell et al., 1996; Osorio et al., 1998). Despite the reason for root-toshoot ratio change, root-to-shoot ratios should not be viewed as a sole indicator of
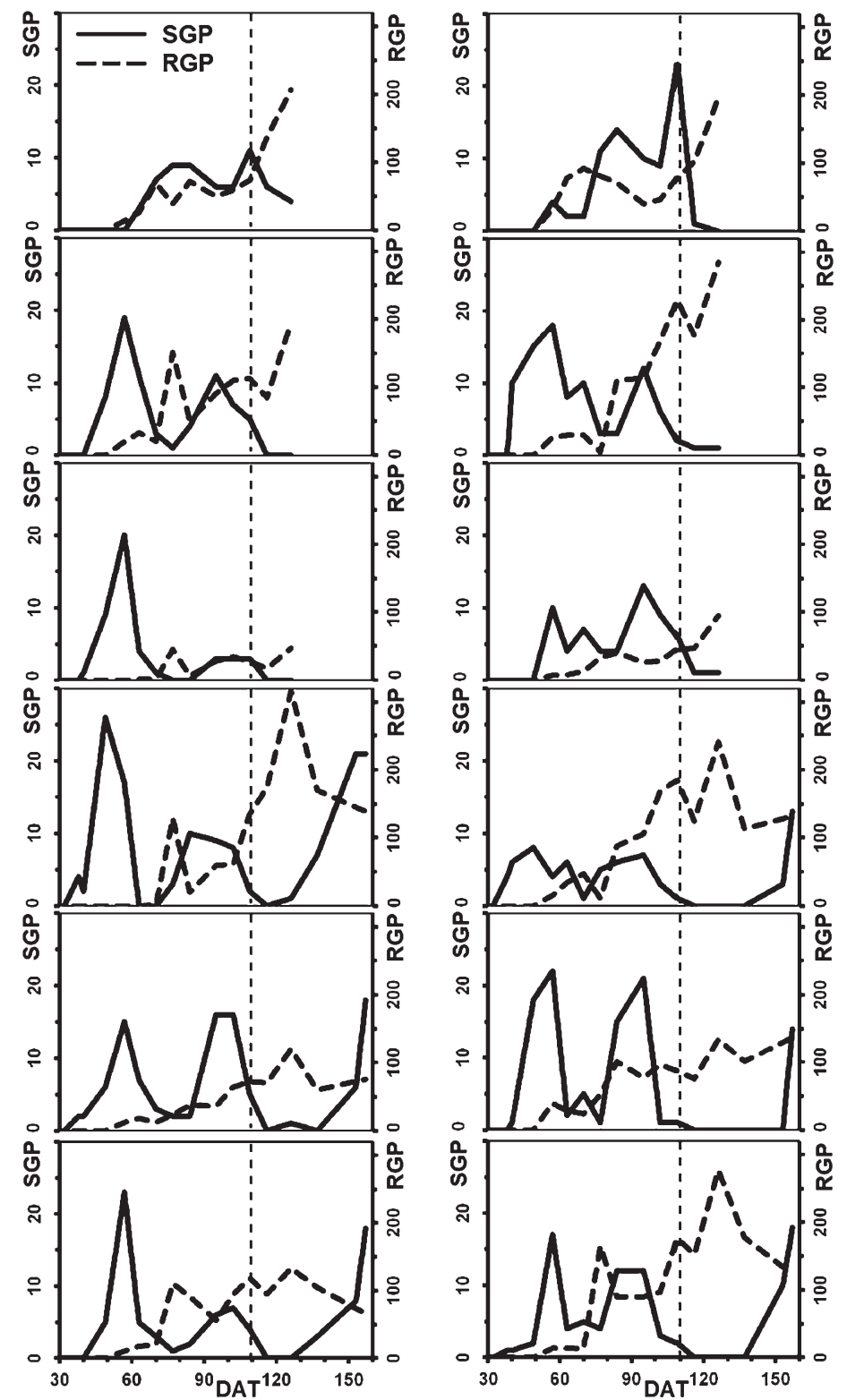

Fig. 3. Growth patterns of Ligustrum japonicum plants grown under a short wet/dry irrigation cycle. Vertical axes are number of root growing points (RGP, broken line) and number of shoot growing points (SGP, continuous line). DAT $=$ days after transplanting. The vertical dotted line marks 110 DAT. Each graph represents one plant replication. Left column graphs are from plants with two shoot flushes before 110 DAT. Right column graphs are from plants with three shoot flushes before 110 DAT. The three upper graphs of each column represent plants harvested at 138 DAT. 
plant water availability during growth. As demonstrated here, growth stage should be considered as an important factor when determining this ratio, especially for episodic species.

Water relations. A commercial substrate was used in the rhizotrons to provide a lightweight, uniform material for root growth and for consistency of substrate water content. Irrigation treatments had similar $\% \mathrm{VWC}_{\text {Sat }}$ (39.0 for LC vs. 37.7 for SC), whereas $\% \mathrm{VWC}_{\mathrm{Min}}$ (34.6 for LC vs. 36.0 for SC) were significantly different between the treatments with the resulting mean $\Delta_{\% \mathrm{VWC}}$ differing by greater than 2-fold (4.5 long vs. 1.7 short). Nemali et al. (2007) examined the efficacy of capacitance-type probes for use in soilless substrates and concluded that these type of sensors provided an accurate measure of VWC when the electric conductivity of irrigation water is less than $1.0 \mathrm{dS} \cdot \mathrm{m}^{-1}$. Differential \%VWC was directly influenced by irrigation frequency; thus, the greater the $\Delta_{\% \mathrm{VWC}}$, the greater the degree of water limitation and therefore water stress experienced by a plant. Although correlations between root dry mass and shoot dry mass were high $(r=0.80)$, individual plant root-to-shoot ratio correlated poorly with $\Delta_{\% \mathrm{VWC}}(r=0.53)$.

On the day of maximum water stress, the $\mathrm{D} g_{\mathrm{S}}$ of LC plants was less than that of SC plants (Fig. 2A). However, the $\mathrm{D}_{\mathrm{S}}$ of LC plants $3 \mathrm{~d}$ after irrigation was similar to the $\mathrm{D} g_{\mathrm{S}}$ of SC plants $2 \mathrm{~d}$ after irrigation (5983 and $6344 \mathrm{~mol} \cdot \mathrm{m}^{-2} \cdot \mathrm{d}^{-1}$, respectively). This indicates that water was available for normal transpiration of LC plants for at least the first $3 \mathrm{~d}$ of a cycle but not the entire period. Concurrent with lower $\mathrm{D}_{\mathrm{S}}$, predawn shoot water potentials were more negative for $\mathrm{LC}$ than for SC plants, whether on a day before irrigation (maximum water stress; Fig. 2B) or on a day after irrigation when water stress was minimum. Midday water potentials were similar between treatments each day but were significantly different between maximum and minimum stress days. More negative predawn water potentials of LC plants likely reduced shoot elongation (Beeson, 1992). A reduction in $\mathrm{D} g_{\mathrm{S}}$ and more negative water potentials at the end of a LC can explain the differences in dry mass.

Root and shoot growth patterns. Similar growth patterns to those observed in this study were not found in the literature nor have growing points of both roots and shoots been used previously to distinguish episodic patterns. During periods of low RGP, root mass increase likely would have been small and likely would have been large during periods of high RGP. Thus, activity of RGP should correspond to traditional dry mass measurements of episodic growth. The initial acclimatization period was required to enable roots to elongate sufficiently to be observed in rhizotron windows. Roots had to grow $\approx 15 \mathrm{~cm}$ to reach the sides of a rhizotron arm. This delayed quantification of RGP relative to SGP (Fig. 3). However, in all plants, root growth occurred before bud swelling. This contrasts with observations for transplanted deciduous species of Quercus alba and Quercus marilandica seedlings, which expanded roots only after shoot expansion (Reich et al., 1980), or in Quercus rubra, which expanded root and shoot simultaneously (Sloan and Jacobs, 2008). Despite variations in flush size and duration between plants, root growth of $L$. japonicum did not completely stop during the experimental period (Figs. 3 and 4). The variation in moisture created by the irrigation cycles affected root tips so that there was always growth in part of the roots in both treatments.

Growth patterns of SC plants were divided into two groups. One pattern had two shoot flushes with a small resting period between them and at least three root flushes without resting periods before 110 DAT (Fig. 3, left graphs). The resting periods between shoot flushes were opposed by a root
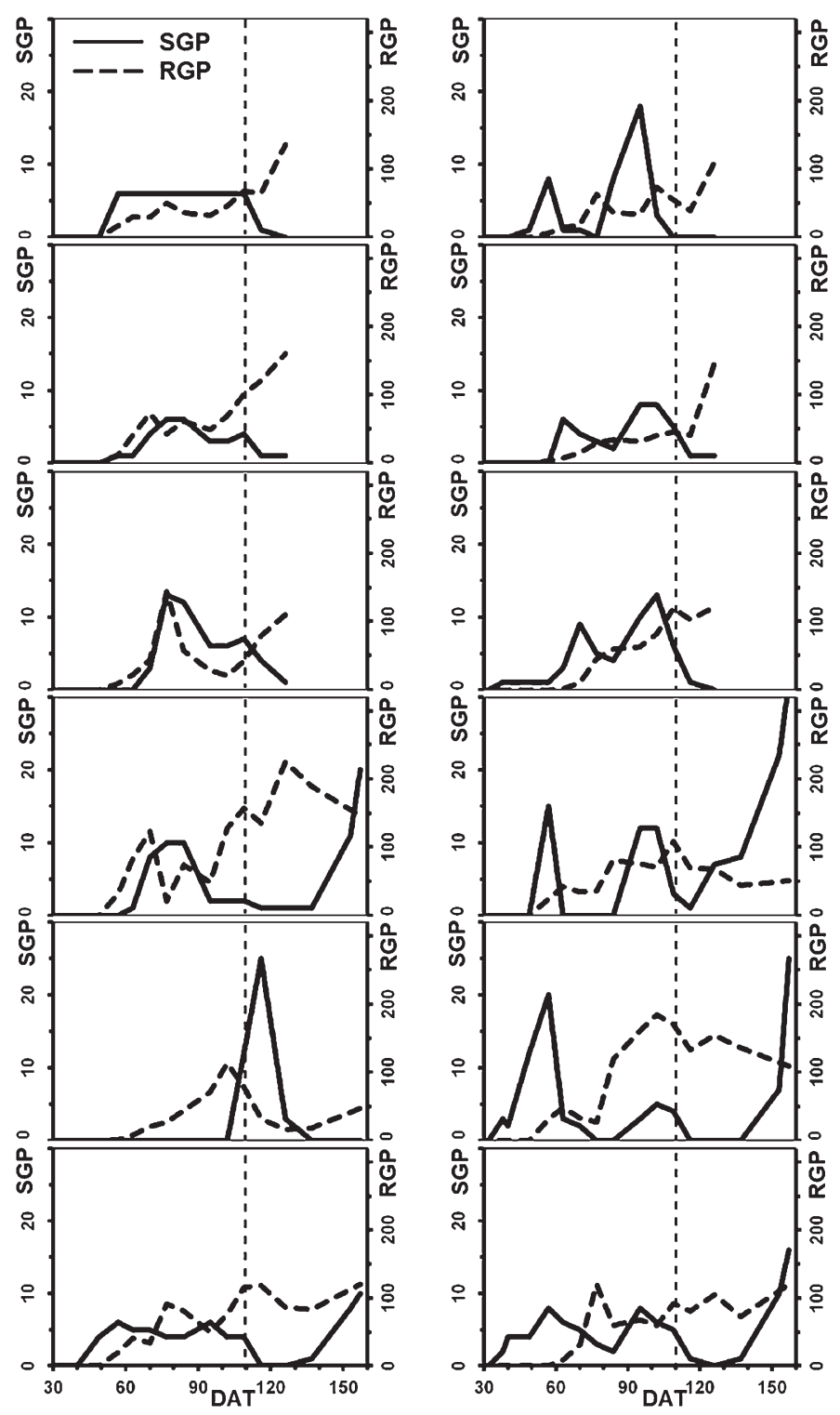

Fig. 4. Growth patterns of Ligustrum japonicum plants grown under a long wet/dry irrigation cycle. Vertical axes are number of root growing points (RGP, broken line) and number of shoot growing points (SGP, continuous line). DAT = days after transplanting. Each graph represents one plant replication. The vertical dotted line signifies 110 DAT. The three upper graphs of each column represent plants harvested at $138 \mathrm{DAT}$.

flush, characterizing episodic growth for at least a short period. The second pattern (Fig. 3, right graphs) had three shoot flushes before 110 DAT and a resting period of $\approx 45 \mathrm{~d}$ before new shoot flush. In both columns, plants represented by the top three graphs were harvested at root flush 138 DAT. Root flushes also had no resting periods in this pattern and episodic growth was not as marked. The resting periods between shoot flushes $\approx 120$ DAT in all plants of SC were opposed to large root flushes, characterizing an episodic behavior. Episodic growth was not as clear in the initial stages but rather in short periods. Woody plants transplanted into landscapes normally extend substantial roots into the soil before shoot growth returns to pre-transplant levels. This predominance of root growth during establishment may have prevailed over genetic-dictated cycles of episodic shoot 
and root growth, suggesting that episodic growth such as previously described by other authors may depend on how well the plants were established as well as genetic-dictated characteristics of the species.

Most plants on LCs had two shoot flushes up until 110 DAT (Fig. 4) and some had only one shoot flush throughout the experiment. In both columns, plants represented by the top three graphs were harvested at root flush 138 DAT. The majority of LC plants displayed growth patterns similar to Pattern A of SC. However, growth patterns in LC plants were more variable. LC delayed the first shoot flush 1 week, although roots began to be visible at the sides of rhizotrons at the same time for both treatments. On average, the first shoot flush started 52 and 45 DAT for LC and SC plants, respectively, whereas the first visible root flush started 58 DAT. The tendency of limited shoot growth more than root growth observed from dry mass and leaf count was also observed with counts of growing points. Cumulative RGPs did not differ between the two treatments (Fig. 5). However, the cumulative SGP of LC was smaller than for SC plants for most of the experimental period. Only after plants had become established, at the last 2 weeks, did LC plants reach the number of cumulative SGPs of SC plants.

\section{Conclusions}

Treatments subjected plants to wetting and drying cycles common in landscape settings. A plant with periodic high water availability has an opportunity to expand growing tissues and implement strategies to tolerate drought that plants under constant stress do not. Such stress can occur in recently transplanted landscapes during periods of limited rainfall and little or no supplemental irrigation.

In response to long irrigation cycles, L. japonicum displayed a clear tendency to delay shoot growth more than root growth. There were no differences in root dry mass between treatments within harvests. However, there was more new shoot dry mass for SC than for LC plants at shoot harvest, as a result of principally a higher number of new leaves. L. japonicum responded to the 7-d irrigation cycles by diminishing production of new leaves and leaf expansion during the establishment period but keeping the same level of root growth as did plants under the 2-d irrigation cycle. Once plants had a more extensive root system, the size of new leaves of both treatments was similar. Water shortage effects in root-to-shoot ratios depended on the stage of growth of a plant (root or shoot flush). Thus, the use of this ratio as a measure of plant establishment or as an indicator of plant water stress has to be considered carefully, especially for episodic species.

Growth patterns varied substantially between individual plants and were not synchronized. Although all plants were clones and purposely selected for visual uniformity, this variability is likely not the result of experimental conditions, but rather previously unreported randomness inherent in living systems. Episodic growth was noted

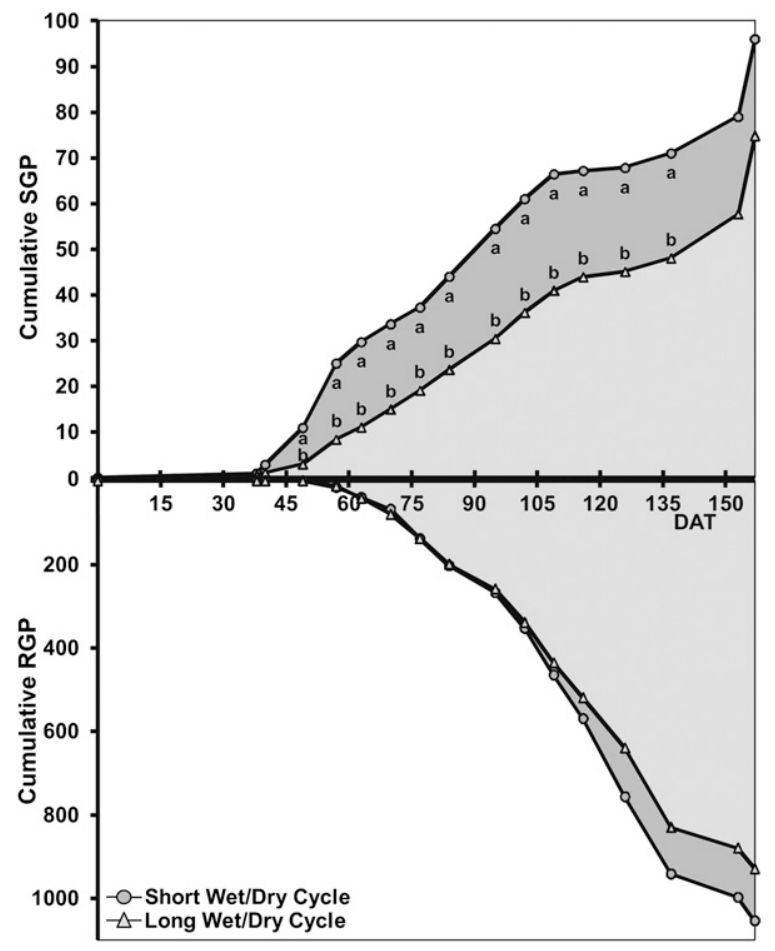

Fig. 5. Cumulative number of root growing points (RGP) and shoot growing points (SGP) of Ligustrum japonicum. DAT = days after transplanting. Each point represents the mean of 12 replications of each irrigation treatment, except for last two points, which represent six replications. Means followed by different letters within each day are different at $P \leq 0.05$ (Fisher's least significant difference). principally after plant establishment; however, there was no clear arresting of RGP during shoot flushes. SC plants started bud expansion earlier than LC and had more shoot flushes and cumulative SGPs. Root growth was similar in both treatments.

\section{Literature Cited}

Abrams, M.D. 1990. Adaptations and responses to drought in Quercus species of North America. Tree Physiol. 7:227-238.

Bachelard, E.P. 1986. Effects of soil moisture stress on the growth of seedlings of three eucalypt species. II: Growth effects. Australian Forest Research 16:51-61.

Beeson, R. 1994. Water relations of field-grown Quercus virginiana Mill from preharvest through containerization and 1 year into a landscape. J. Amer. Soc. Hort. Sci. 119:169-174.

Beeson, R.C. 1992. Restricting overhead irrigation to dawn limits growth in container-grown woody ornamentals. HortScience 27:996-999.

Beeson, R.C. and J. Haydu. 1995. Cyclic microirrigation in container-grown landscape plants improves plant growth and water conservation. J. Environ. Hort. 13:6-11.

Beikircher, B. and S. Mayr. 2009. Intraspecific differences in drought tolerance and acclimation in hydraulics of Ligustrum vulgare and Viburnum lantana. Tree Physiol. 29:765-775.

Chaves, M.M., J.P. Maroco, and J.S. Pereira. 2003. Understanding plant responses to drought; from genes to the whole plant. Funct. Plant Biol. 30:239-264

Dickson, R.E., P.T. Tomlinson, and J.G. Isebrands. 2000. Allocation of current photosynthate and changes in tissue dry weight within northern red oak seedlings: individual leaf and flush carbon contribution during episodic growth. Canadian Journal of Forest Research 30:1296-1307.

Engels, C. 1994. Effect of root and shoot meristem temperature on shoot to root dry matter partitioning and the internal concentrations of nitrogen and carbohydrates in maize and wheat. Ann. Bot. (Lond.) 73:211-219.

Farooq, M., A. Wahid, N. Kobayashi, D. Fujita, and S.M.A. Basra. 2009. Plant drought stress: Effects, mechanisms and management. Agronomy for Sustainable Development 29:185-212.

Farrell, R.C.C., D.T. Bell, K. Akilan, and J.K Marshall. 1996. Morphological and physiological comparisons of clonal lines of Eucalyptus camaldulensis.1. Responses to drought and waterlogging. Aust. J. Plant Physiol. 23:497507.

Gilman, E.F. and R.C. Beeson. 1996. Production methods affects tree establishment in the landscape. J. Environ. Hort. 14:81-87.

Jackson, R.B., J.S. Sperry, and T.E. Dawson. 2000 Root water uptake and transport: Using physiological processes in global predictions. Trends Plant Sci. 5:482-488.

Kozlowski, T.T. and S.G. Pallardy. 2002. Acclimation and adaptive responses of woody plants to environmental stresses. Bot. Rev. 68:270-334.

Kuehny, J.S. and M.C. Halbrooks. 1993. Episodic whole plant growth patterns in Ligustrum. Physiol. Plant. 89:33-39.

Kuehny, J.S., W.B. Miller, and D.R. Decoteau. 1997. Changes in carbohydrate and nitrogen relationships during episodic growth of Ligustrum japonicum Thunb. J. Amer. Soc. Hort. Sci. 122: 634-641.

Maseda, P.H. and R.J. Fernandez. 2006. Stay wet or else: Three ways in which plants can adjust hydraulically to their environment. J. Expt. Bot. 57:3963-3977. 
McMillin, J.D. and M.R. Wagner. 1995. Effects of water-stress on biomass partitioning of Ponderosa pine-seedlings during primary root growth and shoot growth periods. For. Sci. 41:594-610.

Mishio, M. 1992. Adaptations to drought in five woody species co-occurring on shallow-soil ridges. Funct. Plant Biol. 19:539-553.

Nemali, K.S., F. Montesano, S.K. Dove, and M.W. van Iersel. 2007. Calibration and performance of moisture sensors in soilless substrates: $\mathrm{ECH}_{2} \mathrm{O}$ and Theta probes. Sci. Hort. 112:227-234.

Osorio, J., M.L. Osorio, M.M. Chaves, and J.S. Pereira. 1998. Water deficits are more important in delaying growth than in changing patterns of carbon allocation in Eucalyptus globulus. Tree Physiol. 18:363-373.

Reich, P.B., R.O. Teskey, P.S. Johnson, and T.M. Hinckley. 1980. Periodic root and shoot growth in oak. For. Sci. 26:590-598.

Rogers, H.H., S.A. Prior, G.B. Runion, and R.J. Mitchell. 1996. Root to shoot ratio of crops as influenced by $\mathrm{CO}_{2}$. Plant Soil 187:229-248.
Saccardy, K., G. Cornic, J. Brulfert, and A. Reyss. 1996. Effect of drought stress on net $\mathrm{CO}_{2}$ uptake by Zea leaves. Planta 199:589-595.

Scheiber, S.M., E.F. Gilman, M. Paz, and K.A. Moore. 2007. Irrigation affects landscape establishment of burford holly, Pittosporum, and sweet viburnum. HortScience 42:344348.

Sharp, R.E. and W.J. Davies. 1979. Solute regulation and growth by roots and shoots of waterstressed maize plants. Planta 147:43-49.

Sharp, R.E., V. Poroyko, L.G. Hejlek, W.G. Spollen, G.K. Springer, H.J. Bohnert, and H.T. Nguyen. 2004. Root growth maintenance during water deficits: Physiology to functional genomics. J. Expt. Bot. 55:23432351.

Silva, D. and R.C. Beeson, Jr. 2011. A largevolume rhizotron for evaluating root growth under natural-like soil moisture conditions. HortScience 46:1677-1682.

Silva, D.D. 2010. Influence of water stress, nonstructural carbohydrates and free amino acids on control of root and shoot growth of Ligustrum japonicum Thunb. University of Florida, Gainesville, Dissertation, University of Florida Dissertation.

Sloan, J.L. and D.F. Jacobs. 2008. Carbon translocation patterns associated with new root proliferation during episodic growth of transplanted Quercus rubra seedlings. Tree Physiol. 28:1121-1126.

Spomer, L.A. 1974. Two classroom exercises demonstrating the pattern of container soil water distribution. HortScience 9:152-153.

Stabler, L.B. and C.A. Martin. 2006. Irrigation regimens differentially affect growth and water use efficiency of two southwest landscape plants. J. Environ. Hort. 18:66-70.

Steinberg, S.L., J.C. Miller, and M.J. McFarland. 1990. Dry-matter partitioning and vegetative growth of young peach trees under water-stress. Aust. J. Plant Physiol. 17:23-36.

Thornley, J.H.M. 1996. Modelling water in crops and plant ecosystems. Ann. Bot. (Lond.) 77: 261-275. 